$(/)$

TRANG CHỦ » KHOA HỌC - MÔI TRƯÒ̀nG (/KHOA-HOC-MOITRUONG) " KHOA HỌC (/KHOA-HOC)

\title{
i2Metrix - thước đo năng lực đổi mới sáng tạo của doanh nghiệp
}

(ㄷ) $08: 49 \mid 19 / 07 / 2014$

Nếu coi năng lực đổi mới sáng tạo (ĐMST) là trái tim của doanh nghiệp thì việc nhận thức đúng và bắt mạch được nó sẽ là động lực giúp nâng cao sức cạnh tranh của doanh nghiệp trên thị trường. Đó cũng chính là cơ sở cho sự ra đời của Bộ tiêu chí đo lường năng lực ĐMST, cạnh tranh của doanh nghiệp (i2Metrix). Với vai trò như một máy đo nhịp tim, bộ công cụ này sẽ giúp doanh nghiệp định hướng rõ hơn bước đi của mình trong công cuộc ĐMST.

Doanh nghiệp thấy được mình

Đo lường về năng lực ĐMST không phải bây giờ mới được đề cập tới. Ở cấp độ tổng thể nền kinh tế theo quốc gia và vùng lãnh thổ đã có Chỉ số Sáng tạo Toàn cầu (Global Innovation Index, GII) bắt đầu được tính toán từ năm 2007 do Trường Đào tạo kinh doanh INSEAD khởi xướng. Trong báo cáo GII năm 2013, nước ta xếp hạng thứ 76 trên thế giới về chỉ số sáng tạo. Song, theo nhiều chuyên gia, thông qua những đánh giá này, doanh nghiệp trong nước dường như vẫn chưa thấy được điểm hạn chế của mình để từ đó hoàn thiện năng lực ĐMST. 


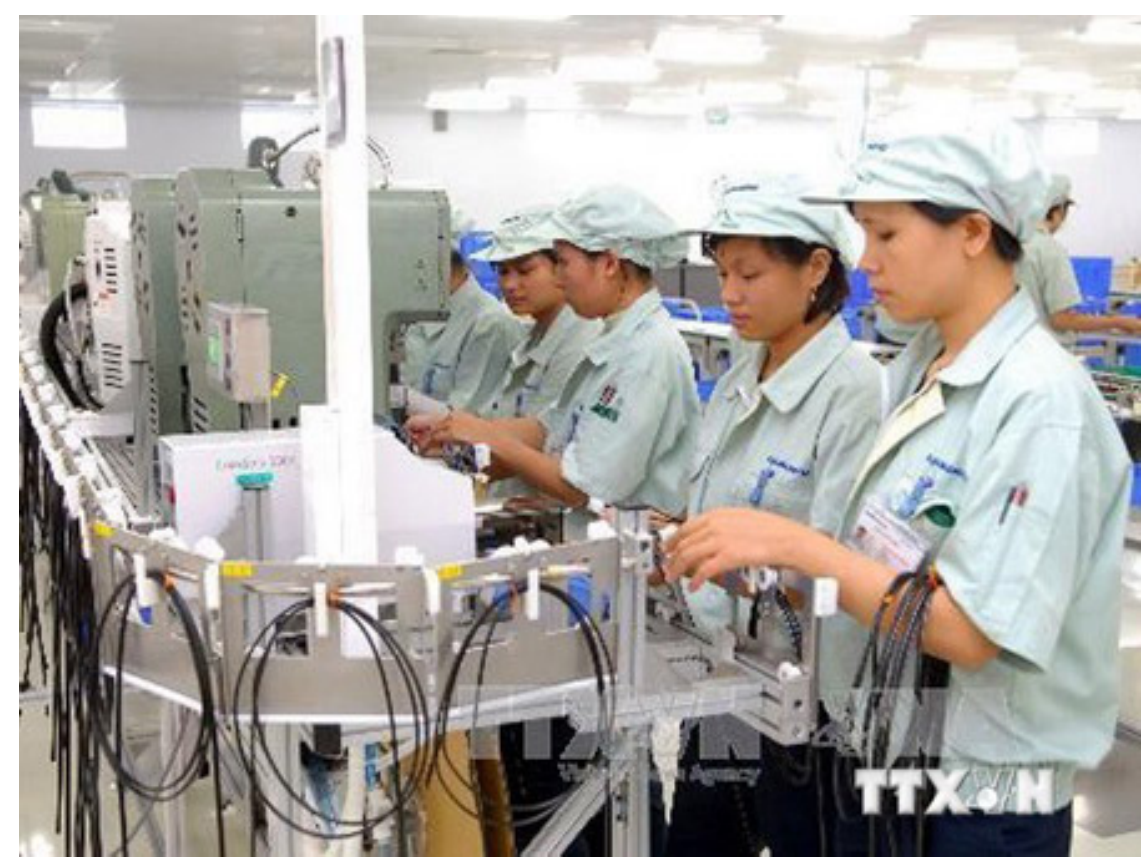

Vậy làm thế nào để doanh nghiệp đo lường được năng lực ĐMST từ đó biết mình nên đi đâu về đâu? Sự ra đời của i2Metrix do Trung tâm Kinh doanh và Hỗ trợ Doanh nghiệp (BSA) và Công ty nghiên cứu kinh tế và tư vấn kinh doanh Dan Houtte, Vuong, Partners Ltd (DHVP) cùng hợp tác phát triển, đã trả lời câu hỏi đó. Khác với những công cụ đánh giá trước đây, i2Metrix ra đời từ thực tiễn và những hiểu biết về môi trường kinh doanh của cộng đồng doanh nghiệp Việt Nam, được tích lũy qua các chương trình hỗ trợ doanh nghiệp và hơn 10 năm nghiên cứu ứng dụng của các chuyên gia quốc tế.

Phó tổng GĐ Công ty CP Saigon Food Lê Thị Thanh Lâm cho rằng, thông qua bộ tiêu chí này, doanh nghiệp sẽ có cái nhìn toàn diện hơn về sức khỏe của mình để kịp thời hoàn chỉnh; đồng thời, có thể rà soát lại hệ thống, quy trình cũng như chiến lược ĐMST. Đơn cử như với Công ty $\mathrm{CP}$ vàng bạc đá quý Phú Nhuận $\mathrm{PNJ}$, ĐMST không chỉ là huy động nhiều hơn nguồn lực mà phải gia tăng lượng thông tin đầu vào bằng việc tăng cường tiếp xúc, trao đổi với đội ngũ nhân viên hoặc tổ chức các cuộc thi ý tưởng. Với SHARES 
Công ty CP Traphaco, ĐMST đi liền với tinh thần trách nhiệm, không phải là việc thế chỗ hàng chục, thậm chí hàng trăm, công nhân bằng dây chuyền tự động mà thay vào đó là phương thức bán hàng thông minh, gần gũi hơn với người tiêu dùng đặc biệt (những người đang đau ốm). Còn với Sài Gòn Food, cùng với việc ứng dụng các tiêu chuẩn đo lường để quản lý nguyên vật liệu hay đầu tư vào nghiên cứu đưa ra thị trường những sản phẩm mới với chất lượng bảo đảm thì ĐMST còn là sự phối hợp đồng bộ giữa quản trị và công nghệ.

Mặt khác, thông qua các tiêu chí đánh giá về sản phẩm đầu ra, nguồn lực và công cụ hỗ trợ, doanh nghiệp sẽ nhận thấy ý nghĩa sống còn của ĐMST không nằm ở doanh thu hay đầu tư về tài chính, nhân lực mà chính là khả năng đi đúng hướng của thị trường. Doanh số cao trong nhiều trường hợp không quan trọng bằng việc kịp thời nhận diện và chuẩn bị đáp ứng nhu cầu mới của người tiêu dùng. Điều này phù hợp với quan điểm phải tiết chế và sử dụng kết quả ĐMST đúng thời điểm của Công ty $\mathrm{CP}$ Vinamit. Ông Nguyễn Lâm Viên, chủ tịch HĐQT của công ty cho biết, tại Vinamit, ĐMST phải làm liên tục còn đem sử dụng lúc nào cũng cần tính kỹ. Khi doanh số sản phẩm truyền thống chững lại là thời điểm đưa ra sản phẩm cải tiến.

Quá sức hay vừa tầm?

Mặc dù bộ tiêu chí này đóng vai trò tích cực đối với hoạt động ĐMST của doanh nghiệp song vẫn còn không ít băn khoăn đặt ra. Có ý kiến cho rằng, bảng câu hỏi của i2Metrix dài và phức tạp vì vậy sẽ khiến doanh nghiệp cảm thấy không hứng thú khi thực hiện hoặc những tiêu chí đưa ra chỉ phù hợp với doanh nghiệp lớn. 
Theo Giám đốc Trung tâm Nghiên cứu kinh doanh và Hỗ trợ doanh nghiệp (BSA) Vũ Kim Hạnh, i2Metrix là phương thức đo lường có cách tiếp cận khách quan để đánh giá lợi ích từ nỗ lực thực thi công việc và không xa rời với bộ tiêu chí của Liên Hợp Quốc cũng như các quốc gia phát triển trong đánh giá năng lực ĐMST. Với những câu hỏi rất cụ thể, bộ công cụ này không chỉ phù hợp với doanh nghiệp có quy mô lớn mà ngay cả những cơ sở nhỏ, đơn vị kinh doanh đặc sản làng nghề cũng hoàn toàn có thể áp dụng để đánh giá năng lực của mình.

Lãnh đạo một doanh nghiệp vừa và nhỏ cũng cho rằng, nhìn nhận bộ tiêu chí này như thế nào phụ thuộc vào từng doanh nghiệp. Nếu doanh nghiệp chuẩn bị sẵn sàng và có tổ chức tốt cho ĐMST thì đây chỉ là một thông lệ bình thường để phát triển. Mặc dù nhiều doanh nghiệp vừa và nhỏ cảm thấy hơi quá sức với bộ chỉ số này do chưa có chương trình ĐMST nhưng chính sự quá sức ấy giúp doanh nghiệp có tầm với, có thể tăng chiều cao của chính mình.

Đặc biệt, đối với những doanh nghiệp địa phương, việc sử dụng bộ công cụ này để đánh giá năng lực của mình càng trở nên cấp thiết. Thực tế cũng cho thấy, thời gian qua đã có không ít doanh nghiệp địa phương sử dụng công cụ i2Metrix để thực hiện đo lường, khảo sát như Cơ sở Chế biến thực phẩm Năm Thụy; Cơ sở Thu mua chế biến hàng thủy sản Tiến Hải hay Công ty CP Rượu Phú Lễ... Tính đến thời điểm hiện tại, bộ công cụ i2Metrix đã tiến hành đo lường, khảo sát 25 doanh nghiệp trên nhiều các lĩnh vực khác nhau. Dự kiến trong thời gian tới, bộ công cụ i2Metrix sẽ làm việc và tiến hành đo lường tại Công ty Bóng đèn phích nước Rạng Đông và Tổng công ty Viễn thông quân đội Viettel.

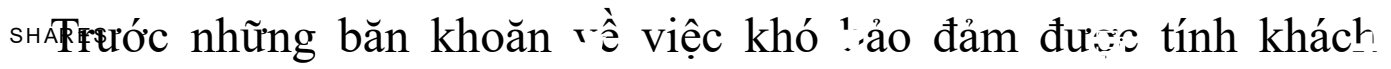


quan khi đánh giá năng lực ĐMST của doanh nghiệp thông qua bộ công cụ này, bà Vũ Kim Hạnh cho biết, để giảm thiểu sai số không đáng có, nguồn đánh giá sẽ bao gồm nhóm nghiên cứu BSA DHVP; doanh nghiệp tự đánh giá; đại diện giới truyền thông; chuyên gia và đại diện người tiêu dùng. Điểm số cho từng chỉ tiêu cụ thể sẽ là giá trị trung bình của điểm số được cho bởi những nguồn này.

i2Metrix xác định năng lực ĐMST của doanh nghiệp qua 10 kích thước. Bao gồm: lợi ích sinh ra từ ĐMST; nguồn nhân lực sáng tạo; nguồn lực tài chính đầu tư cho ĐMST; mức độ hỗ trợ mang tính chất tổ chức đối với định hướng ĐMST; mức độ tạo sự chuyên biệt hóa và khác biệt trong cạnh tranh thị trường; tính thích ứng với xu hướng nhu cầu, tầm nhìn về chu kỳ sống của sản phẩm, sức ảnh hưởng xu hướng; năng lực xử lý thông tin đa tầng tạo hiểu biết để chuẩn bị cho quá trình ĐMST; năng lực xây dựng lõi giá trị văn hóa thích ứng với thay đổi và định hướng ĐMST; khả năng điều phối nhịp nhàng để một ý tưởng được quyết tâm đầu tư đến đích sản phẩm, đưa ra thị trường và cải tiến cho tới bán hàng; năng lực quan sát, dự báo nguy cơ và đánh giá khả năng đáp ứng nguy cơ từ bên trong doanh nghiệp.

\section{Thảo Mộc}

\section{TIN BÀI CÙNG CHUYÊN MỤC}

- JAXA hoãn kế hoạch phóng vệ tinh NanoDragon của Việt Nam vì lý do thời tiết (Jjaxa-hoan-ke-hoach-phong-ve-tinh-nanodragon-cua-viet-nam-vi-ly-do-thoi-tiet)

- Nobel Vật lý 2021 thuộc về 3 nhà khoa học của Mỹ, Đức và Italy (/nobel-vat-ly-2021SHARE thuoc-ve-3-nho-khoa-hoc-cua-mv-duc-va-italy) 
- Úng dụng công nghệ mới nâng cao giá trị chè Shan Việt Nam (/ung-dung-cong-nghemoi-nang-cao-gia-tri-che-shan-viet-nam-ijjmoroyxz-64115)

- Bộ trưởng Bộ Khoa học và Công nghệ Huỳnh Thành Đạt tham dụ̂ Hội nghị các Bộ trưởng Khoa học và Công nghệ (/bo-truong-bo-khoa-hoc-va-cong-nghe-huynhthanh-dat-tham-du-hoi-nghi-cac-bo-truong-khoa-hoc-va-cong-nghe)

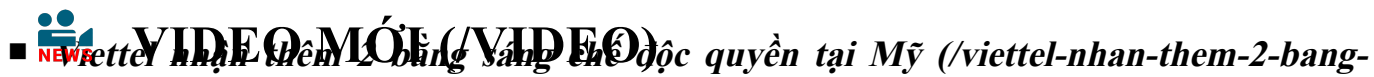

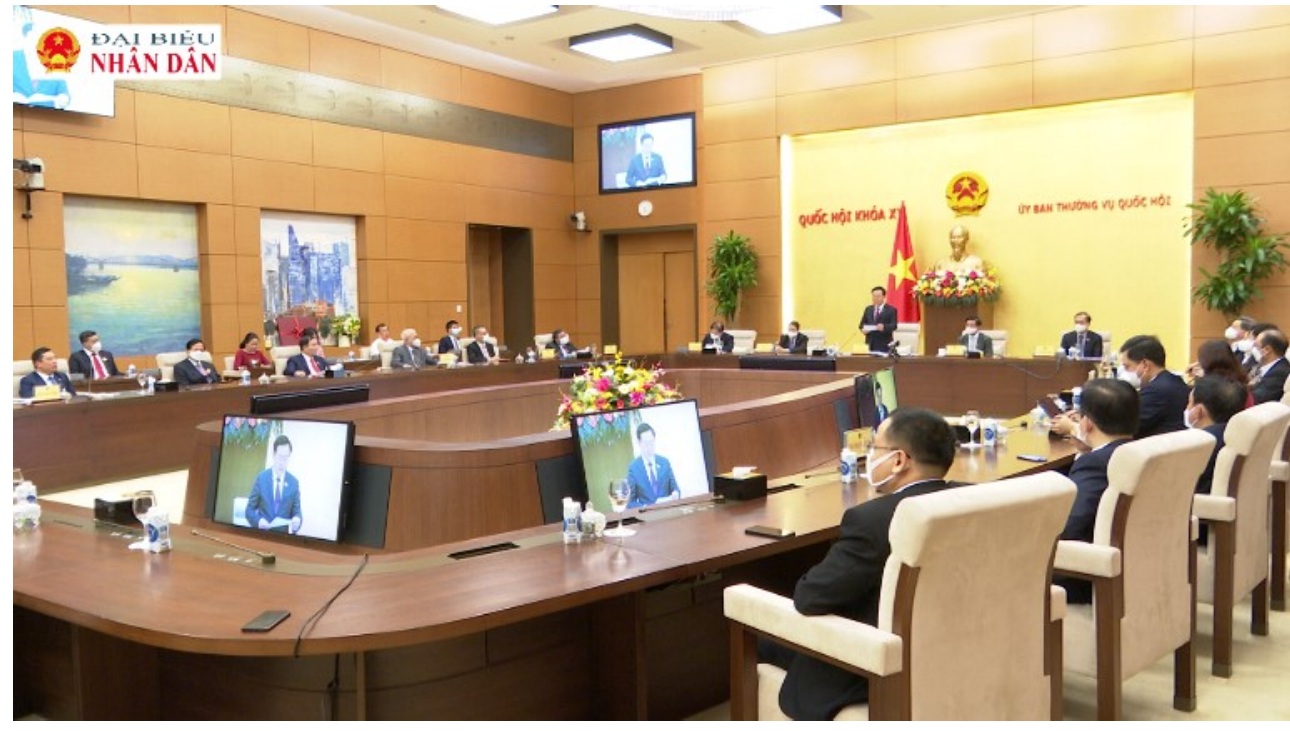

Chủ tịch Quốc hội Vương Đình Huệ gặp mặt đại biểu dự Diễn đàn các nhà Lãnh đạo Doanh nghiệp Việt Nam (/chu-tich-quochoi-vuong-dinh-hue-gap-mat-dai-bieu-du-dien-dan-cac-nhalanh-dao-doanh-nghiep-viet-nam)

\section{畣 ẢNH MỚI (/ANH)}




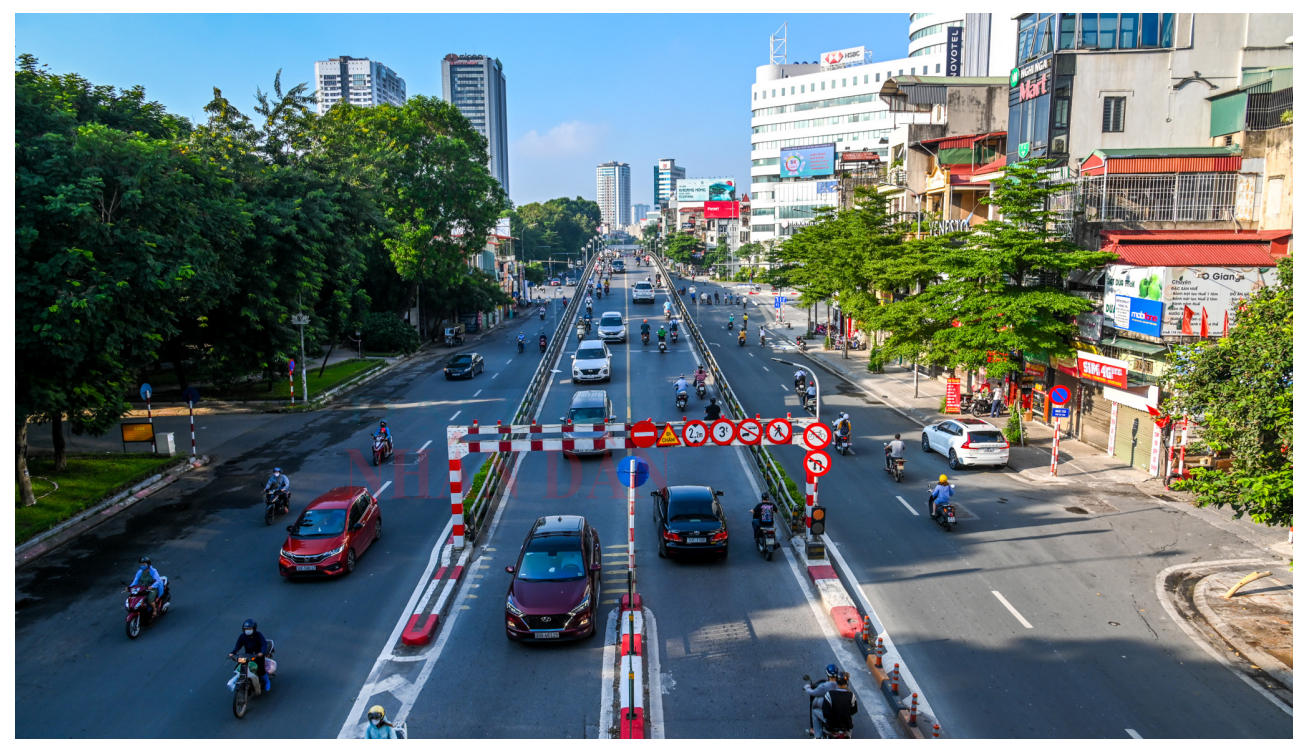

Hà Nội trở lại cuộc sống bình thường sau những ngày giãn cách (/ha-noi-tro-lai-cuoc-song-binh-thuong-sau-nhung-ngay-giancach-5)

\section{TIÊU ĐIỂM}

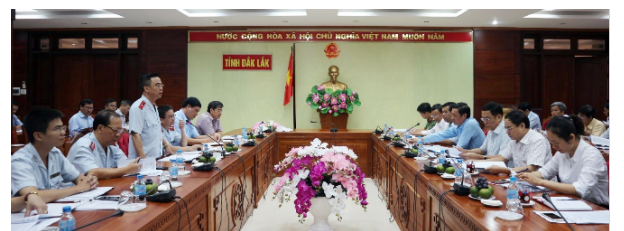

(/giam-sat-kip-thoi-khong-phat-sinh-“diem-

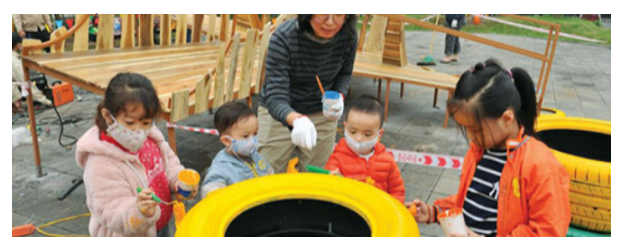

(/khong-gian-chung-ket-noi-cong-dong-

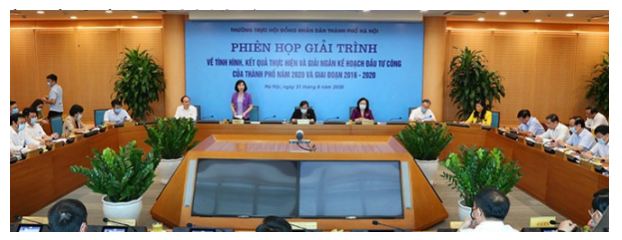

(/bai-cuoitao-khong-khi-dan-chu-cau-thi-

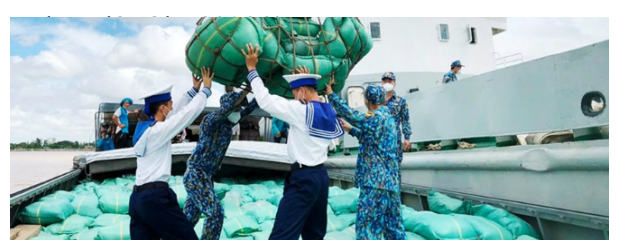

(/chung-suc-phong-chong-va-chien-thang-

SHARES dich-f72kxm931w-64100)
Giám sát kịp thời không phát sinh “điểm nóng" (/giam-sat-kip-thoikhong-phat-sinh-“diem-nong”)

Không gian chung kết nối cộng đồng (/khong-gian-chung-ket-noicong-dong-hprkyalase-64127)

Bài cuối: Tạo không khí dân chủ, cầu thị (/bai-cuoitao-khong-khidan-chu-cau-thi-yxkg5d2u8h64193)

Chung sức phòng, chống và chiến thắng đại dịch (/chung-suc-phongchong-va-chien-thang-dai-dichf72kxm931w-64100) 


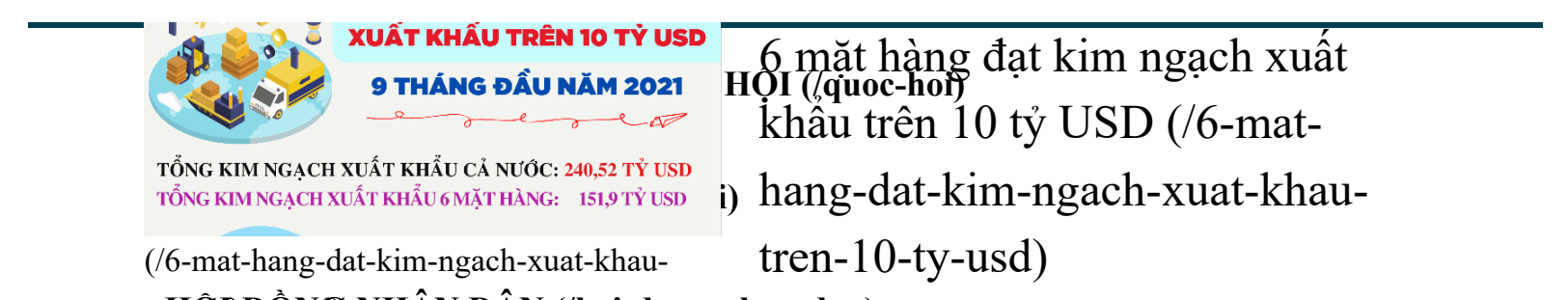

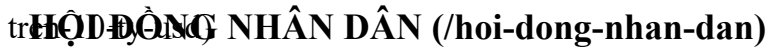

\section{NGH!̣ VIỆN THẾ GIỚI (/nghi-vien-the-gioi) VIDEO/ẢNH (/videoanh)}

\section{LIÊN Hệ (/lien-he) QUẢNG CÁO (/lien-he) GIỚI THIỆU (/gioi-thieu)}

Phó Tổng biên tập Phụ trách: PHẠM THỊ THANH HUYỀN

Phó Tổng biên tập: NGUYẼ̃N QUỐC THẮNG; LÊ THANH KIM

Trụ sở: 35 Ngô Quyền, Hoàn Kiếm, Hà Nội

. Điện thoại: (084) 08046090 (tel:08408046090) - (084) 08046231 (tel:08408046231) (084) 08046012 (tel:08408046012)

.Email: toasoan@dbnd.vn (mailto:toasoan@dbnd.vn), baodientu@dbnd.vn

(mailto:baodientu@dbnd.vn) - Fax: (084) 08046659

Giấp phép số 392/GP_BTTTT Cấp ngày 20/09/2013

. Cơ quan chủ quản: Văn phòng Quốc hội

C Bản quyền 2020 - Đại biểu nhân dân 
